Bryn Mawr College

Scholarship, Research, and Creative Work at Bryn Mawr College

Classical and Near Eastern Archaeology Faculty

Research and Scholarship

Classical and Near Eastern Archaeology

2010

\title{
Approaches to the Study of Personhood in the Early Mycenaean Era
}

James C. Wright

Bryn Mawr College, jwright@brynmawr.edu

Let us know how access to this document benefits you.

Follow this and additional works at: http://repository.brynmawr.edu/arch_pubs

Part of the Classical Archaeology and Art History Commons, and the History of Art, Architecture, and Archaeology Commons

\section{Custom Citation}

Wright, James C. 2010. Approaches to the Study of Personhood in the Early Mycenaean Era. Archaeological Dialogues 17:100-105.

This paper is posted at Scholarship, Research, and Creative Work at Bryn Mawr College. http://repository.brynmawr.edu/arch_pubs/12

For more information, please contact repository@brynmawr.edu. 
from outside, especially when the standards of society were in motion; at this point he might have employed his contacts to set new rules for daily life within the society and be able to become more successful than others beside him. Strictly speaking, we can only detect changes in mortuary practices, but there is every appearance that there also existed some resistance to the new standards, as is indicated by the younger Grave $\Lambda 1$. Its setting, as Voutsaki puts it, 'retains in most respects the traditional practices' (p. 89).

It is these different grave settings which might reflect that there was no coherent discourse among the social elite about virtues and moral standards but rather discord and disagreement. To assume such an internal debate would much better fit Voutsaki's assumption of a change in the Peloponnese from a kin-based and relatively egalitarian society to a ranked and competitive one than the proposed picture of a warrior society led by moral agents. This is because, to all anthropological and psychological knowledge, such deep social and cultural changes cause insecurity and the need for new orientations among the people. In addition we escape the tricky ground of arguing with the Homeric poems. Instead, the suggested reading of the archaeological record is based on transparent methods which are the outcome of welldescribed theories. In this way we get around the methodological trap of furnishing the archaeological record with meanings which are derived only from a biased interpretation of much younger written sources. We should be aware that in such cases ancient historians and archaeologists face the same problems, for written sources do not provide more reliable information than the archaeological record. To attach to our sources any meaning, we need new theory-derived methods - as up to date as the methods which are nowadays applied to analysing the archaeological record.

Archaeological Dialogues 17 (1) 100-105 (C) Cambridge University Press 2010 doi:10.1017/S1380203810000127

\section{Approaches to the study of personhood in the early Mycenaean era James Wright*}

In the brief space allotted for a comment, with respect to the theoretical discussion I will say only that I find the argument insufficiently developed and would rather that Voutsaki had paid closer attention to Dornan's useful critique of Bourdieu and Giddens and the uses to which their sociological theories have been put by archaeologists (Dornan 2002). As a proponent of adding moral philosophy to the archaeological arsenal of theory, Voutsaki might also have dwelt on Walzer's powerful argument about the interrelationship between 'thin' minimizing and 'thick' maximalizing moralities, since they disabuse us of the restraints of our local and universal ideologies and help us understand how individual actors and the groups of

\footnotetext{
* James Wright, Department of Classical and Near Eastern Archaeology, Bryn Mawr College, United States. Email: jwright@brynmawr.edu.
} 
which they are a part are constrained by a plurality of moral decisions. My thoughts here, however, will focus on the case study, since that is the area of my own primary interest and expertise.

The author's purpose in this article is to show how a conception of the self emerged just as the Mycenaean world began to emerge, at the very end of the Middle Bronze Age (on the mainland known as the Middle Helladic $(\mathrm{MH})$ ). She sees personhood focused on changing views of the body. In contrast to a generally undifferentiated matrix of social relations that characterizes the early Middle Bronze Age communities on the mainland of Greece, there now emerge different roles determined primarily by age grade and sex and recognizable in terms of mortuary rituals and their displays, and these show men, women and children taking on specific and individualized roles represented through 'abstract ideals rather than personal achievements' (p. 91). In the comments that follow I show that although I agree with this pursuit, I feel it does not go far enough; in fact the theoretical discussion which informs this case study, especially the notion of moral philosophy as a guide to understanding this process, is at best weakly realized.

Central to Voutsaki's approach is a theoretical turn to the moral construct of Homer's heroes, for use as an instrument to help us uncover Mycenaean personhood. How this is to work, however, is never fully spelled out. As ever with things Homeric, we must be careful not to essentialize this Greek literary construct that has at best ambiguous material correlates with the era under examination (Sherratt 1990; Morris 2001); nevertheless this seems an apt point of departure for exploring a moral code that would help in understanding personhood during the Early Mycenaean period, especially because what follows historically is, first, the proto-literate early Greek era of the Mycenaean palaces (roughly 1425-1190 B.C.) and, second, the Early Iron Age (roughly 1050-650 B.C.), the quintessential outcome of which is Homer's epics composed during the 8th century B.C. By virtue of language and place, the Homeric world is the most appropriate historical analogy for the Mycenaean era. The notion that the Mycenaeans should be considered in terms of the moral universe and according to the heroic ethos of this later time is the best idea of this paper and deserves applause since it promises to advance discussion beyond the outworn typologies we have employed as surrogates for explanation in the scholarship of the Mycenaean Late Bronze Age. But it seems to me the results fall short of the promise. First, ready at hand and necessary, I suggest, is a comparative basis for such a construction, and this is to be found in the contemporary moral and cosmic codes that guided so many of the actors of the 2 nd and 1st millennia B.C., from Egypt through the Eastern Mediterranean and ancient Near East to the Hittites. Mario Liverani, above all, has clarified how these codes permeated behaviour, while at the same time each cultural group and each principal actor had to adjust to different cultural traditions and expectations, and to changing historical and cultural situations (Liverani 2001; 2005). His specific application of reciprocity is most relevant, since it covers the moral issues of gift-giving and exchange in which Voutsaki is interested. Indeed, embedded within any of the neo-substantivist studies of such scholars as Liverani (for Egypt and the Near East during the 2nd millennium B.C.) and S. von Reden (for Homeric through classical Greece) 
is an appreciation that 'economic' actions are concomitant with the moral imperatives of elite practices that have their roots in Bronze Age mores (von Reden 1995). This subject deserves elaboration, but to do so would entail another essay. Suffice to say that the direction for this would be to show how this moral construct evolved out of an ethos that valued hunting and warfare, the companionship of hunting and warring groups, rules of conduct, and attitudes about justice - subjects broached but not developed in Voutsaki's paper.

What to make of the specifics of the case study presented here? We are increasingly indebted to the author for the revitalization of data from the Middle Helladic (MH) as a product of her leadership of the Groningen project Shifting Identities (http://www.mhargolid.nl), and also her ongoing research into the nature of the evidence for the rise of the Mycenaean sociopolitical order in the Argolid (Voutsaki 1995; 1997; 1998; 1999; 2001). Now she emphasizes that the examination of personhood entails consideration of context. It is therefore fundamentally important to be clear about who, what and where we are talking of in terms of persons and their relation to the larger issue of the rise of a distinctly mainland 'Mycenaean' culture. Next it is necessary to identify the kinds of memories that were written in the spaces inhabited by these persons and how those memories were intentional products of individuals and the groups they belong to. The question of intentionality is important because of its utility for any theory of agency. We can demonstrate that from the beginning of the 'Mycenaean' era there is an increasingly potent and much-repeated set of messages that are transmitted, ultimately to larger and broader communities throughout the area we define as the core and periphery of the 'Mycenaean' culture. And we also see them rewritten and passed on to succeeding generations down into the Iron Age. This applies equally or especially to the objects of these persons that were passed on as memorials and legitimizing instruments (e.g. Palaima (1995) on the sceptre of power; and Palaima (2003) on the Linear A inscribed cauldron from Shaft Grave IV and his linking of this antique and foreign object to the 'Cretanmade' tripods recorded in the 13th-century Linear B tablets from Pylos; Bennet 2004). These two examples illustrate the 'who' and the 'what' of personhood during the Early Mycenaean period for they demonstrate the manners by which these persons deployed themselves through objects in time so as to assert their control over a landscape (the 'where') that was populated by persons whose lives were ordered diacritically by these elites. Ultimately, this addition of what were originally individualizing messages and memories over time creates a historical record, and the imprint of that record is what we are trying to piece together in order to try to explain what happened in this era of pre- and protohistories.

Voutsaki is concerned almost exclusively with the occupants of the shaft graves at Mycenae, both those discovered by Schliemann in his famous excavation of 1876 of what is known as Grave Circle A and those of the subsequent Grave Circle B (Schliemann 1878; Mylonas 1973). Beyond this, only a few other instances within the region of the Argolid are taken into account. Voutsaki omits to inform the reader, however, that (1) these burials are reserved within a larger 'Prehistoric Cemetery' that extends in a crescent along a ridge from the area of Circle $\mathrm{B}$ outside the citadel upwards and beyond 
the area of Circle A and that this cemetery contains burials that encompass the Middle and Late Bronze Ages - and for the periods after the Grave Circles includes two monumental built LH III tholos tombs and a number of chamber tombs - and that (2) the total number of graves is limited. In Circle B there are 24 (wholly contained within a built stone perimeter) and for Circle A beyond the traditional Graves I-VI there are several others that are scattered, without any enclosure, to east and west beyond the area of Schliemann's discovery. Of the burials in Circle B, which is slightly earlier than those of Circle A, 13 are wealthy (Graziadio 1991, 430, figure 5) and, in addition to the six extremely wealthy tombs from Circle A, it is these she is focusing on in her discussion of personhood. In fact, then, we are looking at a few actors who all lived within perhaps three to five generations of each other, in other words within a span of memory of a single individual. When we compare the wealth of these few, we discover that they stand far above any other wealthy and high-status persons buried anywhere in Greece at this time. A good example is Grave N:a in Circle B, the wealth factor of which is 345 (none of the others exceed 100; Graziadio 1991, 430). We really are talking about trendsetters who were intentionally shaping the formation of a process that led to the establishment of Mycenae as the primary, if not undisputed, capital of the Mycenaean world.

If I understand Voutsaki properly, she proposes that by combining relational notions of personhood and agency, we would be able to understand the specific articulation of the self, the society and the cosmos in historically situated cases. It is not clear enough to me how she thinks the burial material is to be treated in her discussion. For example, I would think it necessary to explicitly observe that mortuary customs and images of the body are selected by the burying group on the basis of existing conventions and to advance the purposes of the group and its leaders. These conventions are determined by the interactions of the group with other groups; that is, they are culturally determined, but they are also subject to the will of leading individuals, as observable in the individuality of so many of the high-status items deposited in these burials. As Mycenaean society evolves, especially after the conquest of Crete, the leaders of these groups and the leaders of the various communities on the mainland are challenged, for the maintenance and success of their individual selves and the groups and communities they lead, to transform these conventions into something durable and comprehensible to a much wider community (cf. Wright 1987). This involves the transformation of individualizing emblems into societal symbols and narratives that, through a process of symbolic patterning and repetitition, enable the formation of a societal identity (e.g. Bennet and Davis 1999; on emblems, see Wiessner $1983 ; 1984)$. Study of this process, especially when concerned with individual agency and intentionality, requires examination of the styles of the objects from specific and relevant contexts. There is substantial literature on this matter (e.g. Vermeule 1975; Blakolmer 2007), although not oriented to the questions Voutsaki has raised. There is not space here to elaborate on how this works, but Voutsaki herself indicates some important issues in her discussion of the artistic evidence for the relationship of these Early Mycenaean actors to each other and to nature, especially to animals. 
Voutsaki proposes to begin her case study with MH III, which she sees as a critical transitional phase. However, the transformation that Voutsaki sees as crystallizing in the shaft graves at Mycenae actually began earlier at places like Colonna on Aigina, as Kilian-Dirlmeier has exhaustively demonstrated (Kilian-Dirlmeier 1997; Wright 2004b; 2008b) and, though as a phenomenon it may be generalizable, in specific form it is not. Iakovidis tried some years ago to identify the corpus of outstanding burials of LH I date with a generalized process that he termed 'royal burials' across much of the mainland, but the argument does not withstand scrutiny as the evidence displays highly variable rather than uniform burial practices (Iakovidis 1981). Instead the MH IIILH I-II Mycenae burials in every respect stand out as unique, with only a few others in the immediate region that emulate them, those at Lerna and Asine - and they are pale in comparison (Dietz 1980, 34-55 (grave 1971-3); see Wright 2004a for discussion of the social processes behind this emulation). For the purpose of identifying personhood, these burials, as Voutsaki emphasizes, are the most important starting point, but, as just pointed out, they emerge from traditions that had been developing since at least the beginning of the 2nd millennium B.C. Unquestionably, they identify individuals and individual action at the forefront of what came to be during the palace period the symbolic and iconographic characteristics of 'Mycenaean' culture.

Voutsaki's assertion that the treatment of earlier burials, corpses and their grave goods obliterates wealth differences and negates the separate identities of the pre-deceased is suggestive, but unproven. Opening a burial is an opportunity both to respect and memorialize and to rewrite the record. Equally it is an opportunity to commit violence upon the deceased and his or her memory by, for example, desecrating the corpse or robbing it of its valuable grave goods. But that is not what we witness in these early magnificent multiple burials. Surely we must read the quasi-rearticulation of the earlier burial on the east side of Grave $\Gamma$ in Circle B and the careful reassembling of bronze weapons on the west side of the skeletal remains as evidence of continued respect of the original individual buried in the tomb. A more nuanced discussion of this question is warranted with illustrative examples, especially given that the practice of multiple successive burials continues to the end of the Mycenaean era and ultimately includes even outlying commoners in its practice (Wright 2008a). Indeed, the introduction of the practice of multiple successive interments deserves consideration for what it tells us about attitudes towards generational, familial or lineage connections - and any such consideration would be significant for examining the issue of individual and/or burying-group intentionality. These are matters already brilliantly explored by P. Keswani in her studies of the mortuary practices accorded in Cypriot chamber tombs (Keswani 1989; 2004; 2005).

On consumption and removal from circulation Voutsaki makes many good points so it may seem churlish to suggest that they could be sharpened and extended by considering how the amassing of wealth by the individuals in the Mycenae shaft graves, in contrast to all other contemporary burials that we have (and by and large what we have elsewhere is a fairly well-excavated undisturbed collection), is a kind of violence done to others, not just a removal 
from circulation. This is made clear when we inspect the militaristic objects and imagery that dominates these assemblages of what in some cases are probably booty. This is in fact for these few persons a special kind of storage of cultural capital, whose meaning was manifest at several points in time: at the time of acquisition, in aggrandizing displays at times of use (such as diacritical feasts), and subsequently in the continuation through emulation of this kind of violent storage as seen in LH II-IIIA assemblages in richly endowed tholos and chamber tombs all around the Mycenaean world (including Crete, Rhodes and Miletos). In symbolic terms it is also a deployment of emblems, which Wiessner $(1983$; 1984) has famously shown relate first to individual leaders who are trendsetters. Each of these objects has its own tale to tell, a tale linked to its owner and, through inheritance, linked back generations in time (Palaima 2003; Bennet 2004). Individuality, personhood, agency and intentionality are all on display for those who are invited to see. This all changes in LH IIIA when the first palaces are built. The heroic personhood Voutsaki asks us to study in the mortuary remains of these early leaders at Mycenae has become a tradition and a way of life: kingship emerges along with the state, and the individualizing habits of the shaft grave period are gone. Now the rulers are constrained by the needs of the state; its maintenance is more important than their individuality and personhood.

Archaeological Dialogues 17 (1) 105-116 C Cambridge University Press 2010

doi:10.1017/S1380203810000139

\section{Moral theories, Homeric questions - and the shaft graves of Mycenae. A response Sofia Voutsaki*}

I would like to thank Silvia Tomášková, Christoph Ulf and James Wright for their comments, which allow me to clarify and expand my argument. As I cannot address all the points they raise in this response, I have decided to concentrate on three themes: (i) the application of moral theory, (ii) Homeric questions and (iii) the focus on the shaft graves of Mycenae.

\section{The application of moral theory}

The commentators' views on my use of moral theory were divided. Tomášková agrees that moral philosophy can offer refreshing new insights of agency and personhood. Wright feels that my application of moral philosophy is weak, but does not really spell out specific weaknesses. Finally, Ulf does not see at all what moral philosophy has to offer.

Let me therefore explicitly address the question: why moral theory? And why not sociology or social psychology, for example? These, according to Ulf, would be more relevant to my enquiry, and to archaeology and history in general. To start with, because most sociological studies deal only

\footnotetext{
* Sofia Voutsaki, Groningen Institute of Archaeology (GIA), Groningen, the Netherlands. Email: s.voutsaki@rug.nl.
} 